\title{
POTENSI MEDIA SOSIAL DALAM MEMPOPULERKAN KONTEN SAINS ISLAM
}

\author{
Irwandani
}

Fakultas Tarbiyah dan Ilmu Keguruan IAIN Raden Intan Lampung; Email: irwandani@radenintan.ac.id

Diterima: 20 September 2016. Disetujui: 18 November 2016. Dipublikasikan: Desember 2016

\begin{abstract}
The development of internet users in Indonesia is very rapid. In the last five years the number of internet users increased by $430 \%$. By the end of 2015, internet users in Indonesia have reached 88.1 million people. As many as 90\% of internet users are social media users.Based on statistical reports there are about $92 \%$ of social media users aged between 13-39 years old. That means that there are about 73 million social media users who have the potential to popularize the content of Islamic science in social media. Islamic science was born out of the spirit of Muslim scientists and academics to integrate Islam and science / science. There is some content of Islamic science that can be packed in social media: 1) Content of science in Islam, 2) Content of Muslim inventors 3) Content review of the latest findings in Islamic view, 3) Content wise words of the Scientists.
\end{abstract}

\begin{abstract}
Abstrak
Perkembangan pengguna internet di Indonesia sangat pesat. Dalam lima tahun terakhir jumlah pengguna internet meningkat sebesar 430\%. Pada akhir 2015, pengguna internet di Indonesia telah mencapai 88,1 juta orang. Sebanyak $90 \%$ pengguna internet adalah pengguna media sosial. Berdasarkan laporan statistik ada sekitar $92 \%$ pengguna media sosial berusia antara 13-39 tahun. Itu berarti ada sekitar 73 juta pengguna media sosial yang berpotensi mempopulerkan konten sains Islam di media sosial. Sains Islam lahir dari semangat ilmuwan dan akademisi Muslim untuk mengintegrasikan Islam dan sains/sains. Ada beberapa konten sains Islam yang bisa dikemas dalam media sosial: 1) Konten sains dalam Islam, 2) Konten penemu Muslim 3) Kajian isi temuan terbaru dalam pandangan Islam, 3) Konten kata-kata bijak dari Ilmuwan.
\end{abstract}

Kata kunci:media sosial, sains Islam

(C) 2016 URPI, FTK IAIN Raden Intan Lampung

\section{PENDAHULUAN}

Perkembangan pengguna internet di Indonesia terbilang sangat pesat. Dalam 5 tahun terakhir, jumlah pengguna internet di Indonesia naik sebesar $430 \%$ (Paragian, 2014). Indonesia berada di peringkat kedua setelah Filipina dalam hal pesatnya pertumbuhan pengguna internet di dunia. Berdasarkan laporan Simon Kemp dalam Southeast Asia Digital in 2015, hingga November 2015 pengguna internet telah mencapai 88,1 juta orang atau sekitar $34 \%$ dari total jumlah penduduk Indonesia.

Pesatnya perkembangan tersebut dipengaruhi oleh semakin populernya penggunaan media sosial di kalangan masyarakat. Dari jumlah total pengguna internet di Indonesia, sekitar 90\% (79 juta) adalah pengguna media sosial (Kemp, 2015). Adapun media sosial yang paling banyak di akses adalah Facebook, Twitter, Path, dan Instagram (Noviadhista, 2016).

Salah satu contoh media sosial terbesar dan banyak penggunanya adalah media sosial Facebook. Berdasarkan usia pengguna, sekitar $77 \%$ pengguna media sosial ini berusia di bawah usia 30 tahun. Sekitar $16 \%$ sisanya berada di atas 40 tahun. Berikut disajikan sebaran usia pengguna media sosial Facebook berdasarkan data dari We Are Social tahun 2015.

Tabel 1. Sebaran Usia Pengguna Media Sosial di Indonesia

\begin{tabular}{c|c|c}
\hline Usia & Jumlah & \% \\
\hline 13-19 tahun & 26 juta & 33 \\
\hline 20-29 tahun & 35 juta & 44 \\
\hline 30-39 tahun & 12 juta & 15 \\
\hline 40-49 tahun & 3,8 juta & 0,05 \\
\hline 50-59 tahun & 1 juta & 0,01 \\
\hline 60 tahun ke atas & 1,5 juta & 0,02 \\
\hline
\end{tabular}


Berdasarkan data di atas, ada sekitar $33 \%$ pengguna media sosial berada di rentang usia 13-19 tahun. Kita ketahui bahwa rentang tersebut merupakan rentang anak usia sekolah. Berdasarkan data dari Badan Pusat Statistik, pada tahun 2013 terdapat sekitar 45 juta anak usia sekolah. Jika kita asumsikan pada tahun 2013 terdapat 20 juta anak sudah mengenal internet dan media sosial, maka itu berarti pada tahun 2013 sudah sekitar $40 \%$ anak usia sekolah yang sudah menjadi pengguna media sosial.

Besarnya pengguna media sosial dari kalangan usia sekolah (pelajar dan mahasiswa) ternyata tidak berbanding lurus dangan banyaknya jumlah konten yang seharusnya didapatkan oleh kalangan tersebut. Memang belum banyak data yang secara spesifik menganalisis jenis dan sebaran konten di media sosial. Namun, berdasarkan hasil observasi yang telah dilakukan oleh peneliti melalui pencarian kata-kata kunci populer atau sering dikenal dengan istilah hashtag di media sosial Instagram, diperoleh kesimpulan bahwa konten yang bernuansa pendidikan, sains dan sejenisnya masih terbilang sangat jarang dibandingkan dengan konten lain. Sebagian besar konten di media sosial adalah konten-konten bernuansa hiburan, perdagangan, permainan hingga menjurus kepada konten bermuatan negatif seperti kekerasan dan pornografi.

Metode yang digunakan pada penelitian ini adalah analisis deskriptif. Analisis yang dilakukan berdasarkan beberapa sumber diantaranya: media instagram, internet, jurnal dan buku. Berbagai sumber yang telah dikumpulkan kemudian dianalisis oleh peneliti.

\section{PEMBAHASAN}

Data penelusuran dari beberapa konten dan konten populer dengan kata pencarian acak pada media sosial instagram berdasarkan akses terakhir pada Juli 2016 disajikan pada tabel 2.
Tabel 2. Konten Populer di Media Sosial Instagram

\begin{tabular}{c|l|r}
\hline No & \multicolumn{1}{|c}{$\begin{array}{c}\text { Kata } \\
\text { Pencarian } \\
\text { (Hashtag) }\end{array}$} & $\begin{array}{c}\text { Jumlah Kiriman } \\
\text { yang Terindex } \\
\text { (dalam ribu) }\end{array}$ \\
\hline 1. & Sains & 21,2 \\
\hline 2. & Sains Islam & 0,11 \\
\hline 3. & Humor & $7.493,2$ \\
\hline 4. & Liburan & 988,1 \\
\hline 5. & Jualan & $16.467,1$ \\
\hline 6. & Kuliner & $2.732,7$ \\
\hline 7. & Wisata & 560,2 \\
\hline 8. & Pendidikan & 77,1 \\
\hline 9. & Biologi & 38,2 \\
\hline 10. & Matematika & 42,4 \\
\hline 11. & Kimia & 39,1 \\
\hline 12. & Fisika & 12,3 \\
\hline
\end{tabular}

Berdasarkan Tabel 2, sebagai contoh perbandingan konten yang mengandung kata kunci "sains" dengan kata kunci "humor", diperoleh perbandingan sekitar 1:342. Hal ini menunjukkan bahwa jika ada 343 konten yang diunggah oleh pengguna media sosial, ada 342 yang bernuansa humor dan hanya ada satu saja konten yang bernuansa sains. Ini belum termasuk dengan perbandingan dengan konten populer lainnya, serta perbandingan dengan jumlah konten secara keseluruhan.

\section{Potensi Media Sosial}

Berdasarkan hasil observasi, dapat diperoleh gambaran secara umum bahwa konten sains masih begitu minim dan belum populer dibandingkan dengan konten yang lain. Apalagi konten sains yang dikaitkan dengan Islam. Hal ini tentu menjadi peluang dan tantangan tersendiri.Media pembelajaran berbantuan media sosial bisa dijadikan alternatif pembelajaran fisika karena sifatnya yang bisa diakses kapan saja dan dimana saja. (Irwandani \& Juariah, 2016).

Sosial media adalah $\begin{array}{r}\text { sebuah } \\ \text { jejaring }\end{array}$
komunitas virtual atau para pengguna
yangmemungkinkan pana
didalamnya untuk berinteraksi satu sama
lain, membangun komunitas dan berbagi
ide dan informasi. (Al-Bahrani \& Patel,
2015). Saat ini, jejaring sosial merupakan
bentuk media sosial yang paling banyak


digunakan oleh masyarakat di seluruh dunia. Jejaring sosial adalah suatu struktur sosial yang dibentuk dari simpul-simpul (yang umumnya adalah individu atau organisasi) yang diikat dengan satu atau lebih tipe relasi spesifik seperti nilai, visi, ide, teman, keturunan, dan lain-lain (Nurkamid, 2016).

Saat ini sudah ada lebih dari 20 macam media sosial yang telah ada di dunia. Beberapa diantaranya yang terkenal dan mempunyai banyak pengguna adalahFacebook, Twitter, Instagram, WhatsApp, BBM, Line, Path, Google+, dan sebagainya. Semua jejaring sosial tersebut mempunyai kelebihan dan karakteristik masing-masing. Adapun karakteristik media sosial secara umum sebagai berikut. (Wikipedia, 2016)

1. Pesan yang disampaikan tidak hanya untuk satu orang saja namun bisa ke pelbagai banyak orang contohnya pesan melalui SMS ataupun internet.

2. Pesan yang di sampaikan bebas, tanpa harus melalui suatu Gatekeeper (perantara).

3. Pesan yang di sampaikan cenderung lebih cepat di banding media lainnya.

4. Penerima pesan yang menentukan waktu interaksi.

\section{Sains Islam (Islamic Sains)}

Sains Islam lahir dari semangat untuk melakukan integrasi antara Islam dan ilmu pengetahuan. Umat Islam membutuhkan "sains Islam" karena kebutuhan-kebutuhan, prioritas-prioritas, dan perhatian masyarakat muslim berbeda dari apa yang dimiliki oleh peradaban Barat (Sardar, 1998). Umat Islam membutuhkan sains Islam karena suatu peradaban tidak akan sempurna apabila tidak memiliki suatu sistem objektif untuk memecahkan masalah yang dibingkai sesuai paradigmanya sendiri (Anshori \& Abidin, 2014). Masih menurut Anshori tanpa "sains Islam", masyarakat muslim hanya akan menjadi bagian dari kebudayaan dan peradaban lain (Barat).
Sebenarnya sains Islam bukanlah sesuatu yang baru dalam sejarah peradaban manusia. Sains Islam pernah berjaya jauh sebelum bangkitnya masyarakat Eropa (Barat). Sains Islam abad modern ini sebenarnya merupakan upaya untuk melanjutkan tradisi ilmiah yang telah dikembangkan oleh para Ilmuwan Muslim. Sains digagas dalam kendali agama agar ilmu pengetahuan tidak tumbuh secara liar dan bebas nilai. Sains modern (Barat) membawa tata nilai peradaban modern, yakni materialisme dan kisah tragis kematian Tuhan (Purwanto, 2015). Sains Islam bertujuan untuk mengantarkan seseorang kepada pemahaman yang lebih mendalam terhadap ayat-ayat Allah, baik ayat qauliyah maupun ayat kauniyah. Berdasarkan pemahaman tersebut, diharapkan manusia mampu meningkatkan keimanan dan ketakwaan terhadap kekuasaan Allah sehingga penerapan atas pengetahuan tadi mendatangkan manfaat bagi alam semesta, bukan sebaliknya. Dengan kata lain, bangunan sains Islam secara keseluruhan harus berdasar dan merupakan pengejawantahan prinsip tauhid yang bersumber pada wahyu (Purwanto, n.d.).

Mempopulerkan Sains Islam bisa dipandang sebagai upaya untuk melawan sains modern yang terkenal sekuler. Sebagian kalangan berpendapat bahwa sains modern dianggap paling bertanggung jawab atas segala krisis dan kerusakan yang terjadi di muka bumi, seperti penggunaan senjata nuklir, kebakaran hutan, krisis air, pemanasan global dan sebagainya. Karakteristik Sains Islam yang memadukan antara potensi nalar, akal dan wahyu serta dzikir dan fikir diharapkan akan menghasilkan ilmu pengetahuan yang betul-betul mendatangkan manfaat bagi kepentingan umat manusia dan semesta alam sesuai dengan cita-cita Islam rahmatan lil'alamin. 
Sains Islam dalam kajian ini, difokuskan pada ilmu alam/eksakta yang meliputi kajian matematika, fisika, kimia dan biologi yang berbasis dengan nilainilai keislaman.

\section{Konten Sains Islam dalam Media Sosial}

Konten adalah informasi yang tersedia melalui media atau produk elektronik (Wikipedia, 2016). Konten Sains Islam dalam media sosial berarti segala informasi berkenaan dengan sains Islam yang disesuaikan dengan kemasan media sosial. Jenis media yang disajikan bisa berbentuk tulisan, gambar, animasi, audio, video serta bisa berupa kombinasi dari beberapa bentuk. Hal ini bergantung pada konten apa yang akan disampaikan. Berikut disajikan kelompok konten yang bisa dijadikan alternatif untuk dikembangkan di media sosial.
Kata Bijak Para Ilmuwan
Sains dalam Islam

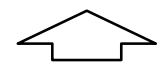

SAINS ISLAM DALAM MEDIA SOSIAL

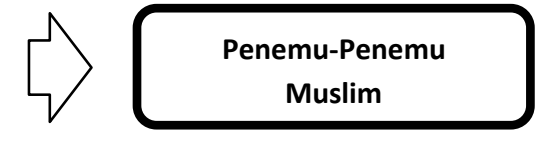

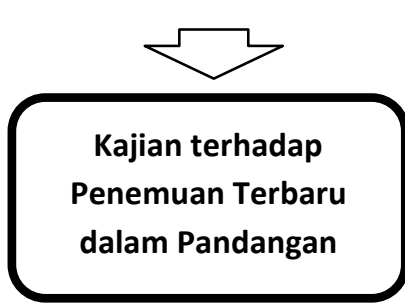

Gambar 1. Konten Sains Islam untuk Media Sosial

\section{Konten Sains dalam Islam}

Pada konten ini, informasi tentang ilmu pengetahuan yang selama ini ada dan berkembang dalam ilmu Matematika, Fisika, Kimia dan Biologi dikaitkan dengan nilai-nilai keislaman. Pengemasan konten ini dalam media sosial bisa berupa tulisan maupun gambar.

\section{Konten Penemu-Penemu Muslim}

Pada konten ini, disajikan informasi tentang biografi singkat para penemu dan ilmuwan muslim, baik dari masa lalu maupun masa sekarang yang telah memberikan sumbangsih bagi perkembangan ilmu pengetahuan. Pengemasan konten ini dalam media sosial bisa berupa kombinasi antara tulisan dan gambar maupun video singkat mengenai perjalanan hidup sang ilmuwan.

\section{Konten Kajian Penemuan/fenomena Terbaru dalam Pandangan Islam}

Pada konten ini, disajikan informasi berupa kajian atas fenomena/penemuan terbaru dalam pespektif Islam. Pengemasan konten ini bisa berupa tulisan, gambar maupun video.

\section{Konten Kata Bijak Ilmuwan}

Pada konten ini disajikan kata bijak maupun kata motivasi yang pernah diucapkan dari para ilmuwan baik muslim maupun nonmuslim sebagai bahan motivasi bagi para pengguna media sosial. Penyajian konten ini bisa berupa perpaduan antara gambar dan tulisan.

\section{Potensi Media Sosial Bagi Perkembangan Sains Islam}

Berdasarkan analisis yang telah diuraikan, potensi media sosial dalam 
mempopulerkan konten sains Islam di Indonesia sangatlah besar. Besarnya potensi ini tentu harus bisa dimanfaatkan secara maksimal agar esensi dari konten sains Islam bisa tersampaikan dengan baik dan tepat sasaran. Berikut disajikan rambu yang perlu diperhatikan agar konten sains Islam di media sosial bisa maksimal.

1. Gunakan bahasa yang sederhana dan mudah diterima semua kalangan.

2. Hendaknya pembahasan yang disajikan tidak terlalu panjang dan bertele-tele.

3. Jika menggunakan konten video, perhatikan durasi. Video yang baik mempunyai durasi yang proporsional sesuai dengan konten yang dikaji.

\section{SIMPULAN}

Potensi media sosial dalam mempopulerkan konten sains Islam di Indonesia sangat besar. Hal ini dikarenakan jumlah pengguna media sosial di Indonesia mencapai 79 juta pengguna (Badan Pusat Statistik, 2015). Dari 79 juta pengguna sekitar $33 \%$ pengguna berada di rentang usia sekolah (Pelajar dan Mahasiswa).

Setidaknya ada 4 (empat) subkonten sains Islam yang bisa dikembangkan di media sosial:

1. Konten sains dalam Islam

2. Konten penemu-penemu muslim

3. Konten kajian penemuan/ fenomena terbaru dalam pandangan Islam

4. Konten kata bijak Ilmuwan

\section{DAFTAR PUSTAKA}

Al-Bahrani, A., \& Patel, D. (2015). Incorporating Twitter, Instagram, and Facebook in Economics Classrooms. The Journal of Economic Education, 46(1), 56-67.

Anshori, \& Abidin, Z. (2014). Format Baru Hubungan Sains Modern dan Islam (Studi Integrasi Keilmuan Atas UIN Yogyakarta dan Tiga Universitas
Islam Swasta Sebagai Upaya Membangun Sains Islam Seutuhnya Tahun 2007-2013. Jurnal UMY.

Badan Pusat Statistik. (2015). Statistik Pendidikan 2014: Hasil Survey Sosial Ekonomi Nasional. Jakarta: BPS.

Irwandani, I., \& Juariah, S. (2016). Pengembangan Media Pembelajaran Berupa Komik Fisika Berbantuan Sosial Media Instagram Sebagai Alternatif Pembelajaran. Jurnal Ilmiah Pendidikan Fisika Al-BiRuNi 05, 5(April), 33-42.

Kemp, S. (2015). Southeast Asia Digital in 2015. Retrieved from http://wearesocial.com/uk/

Noviadhista, U. (2016). No Title. Retrieved from http://www.techno.id/technews/90-persen-pengguna-internet-diindonesia-aktif-di-medsos1601317.html

Nurkamid, M. (2016). Pemanfaatan Aplikasi Jejaring Sosial Facebook untuk Media Pembelajaran. Kudus: Jurnal UMK.

Paragian, Y. (2014). No Title. Retrieved from https://id.techinasia.com/dalam5-tahun-terakhir-jumlah-penggunainternet-indonesia-naik-430-persengrafik

Purwanto, A. (n.d.). Nalar Ayat-Ayat Semesta. Bandung: Mizan.

Purwanto, A. (2015). Ayat-Ayat Semesta: Sisi-Sisi Al Qur'an yang Terlupakan. Bandung: Mizan.

Sardar, Z. (1998). Jihad Intelektual: Merumuskan Parameter-parameter Sains Islam. Surabaya: Risalah Gusti.

Wikipedia. (2016). No Title. Retrieved from

https://id.wikipedia.org/wiki/Media_so sial 